Fecha de recepción: 20 de enero de 2021

Sugerencia de citación: Bandieri, S. (2021). Estrategias económicas de los grupos familiares magallánicos en la Patagonia argentina: el caso de los Braun-Menéndez Behety y"La Anónima". tiempo\&economía, 8(2), 15-47.

https://doi.org/10.21789/24222704.1745
DOI:

https://doi.org/10.21789/24222704.1745

\title{
Estrategias económicas de los grupos familiares magallánicos en la Patagonia argentina: el caso de los Braun-Menéndez Behety y "La Anónima"
}

\author{
Magellan family-owned business groups: \\ The case of the Braun-Menéndez Behety \\ and "La Anónima"
}

\section{Susana Bandieri}

Doctora en historia, investigadora principal del CONICET en el Instituto Patagónico de Estudios de Humanidades y Ciencias Sociales (IPEHCS), Universidad Nacional del Comahue, Argentina https://orcid.org/0000-0003-0766-8516 susana.bandieri@gmail.com

\section{RESUMEN}

Las estrategias económicas de los grupos magallánicos en la Patagonia argentina, con especial atención a la familia Braun-Menéndez Behety, desde finales del siglo XIX hasta la actualidad, se caracterizan por una amplia gama de inversiones diversificadas tanto en la ocupación de tierras para la producción ganadera como en la creación de establecimientos comerciales en las localidades más importantes del sur del país, hoy extendidas a varios 
puntos del conjunto nacional, a través de la Sociedad Anónima Importadora y Exportadora de la Patagonia, más conocida como "La Anónima". A ello se suman la operación de los primeros frigoríficos ovinos, distintas actividades financieras y una eficaz participación en diversos emprendimientos (líneas aéreas, navegación, servicios de telecomunicaciones, empresas editoriales, entre otras), hoy más concentrados en la actividad supermercadista y su logística específica. Distintas estrategias aplicadas en la larga duración le han permitido a esta sociedad convertirse en la actualidad en un exitoso ejemplo de conductas empresariales de carácter familiar en el país.

Palabras clave: diversificación, empresas magallánicas, Patagonia argentina, historia económica.

Códigos JEL: D21, G34, H32, L11, M13.

\section{ABSTRACT}

The economic strategies of the Magellanic groups in the Argentinian Patagonia, with special attention to the Braun-Menéndez Behety family, from the end of the 19th century to these days, are characterized by a wide range of diversified investments - both in the occupation of land for the livestock production and the creation of commercial establishments in the most important towns in the southern region of the country-, which are today extended to various parts of the national whole through the Sociedad Anónima Importadora y Exportadora de la Patagonia, better known as "La Anónima." Added to this is the operation of the first sheep meat processing plants, different financial activities, and effective participation in various undertakings (airlines, navigation, telecommunications services, publishing companies, among others), today more focused on the supermarket activity and its specific logistics. Different strategies applied in the long term have allowed this economic group to become a successful example of family business conducts in the country.

Keywords: Diversification, Magellanic business groups, Argentinian Patagonia, economic history.

JEL Codes: D21, G34, H32, L11, M13. 


\section{INTRODUCCIÓN}

Se analizará en este trabajo el origen y la expansión en la Patagonia argentina de las empresas constituidas por grupos radicados en la ciudad portuaria de Punta Arenas, en el sector chileno del estrecho de Magallanes, con especial atención al caso de la familia Braun-Menéndez Behety. Con un claro ejemplo de inversiones multi-implantadas, estos grupos -inicialmente pequeños y medianos empresarios - incursionaron desde la segunda mitad del siglo XIX en inversiones diversas en el área más austral del continente, comenzando con la ocupación de campos y las explotaciones ganaderas, hasta derivar en una serie de actividades industriales, financieras, de servicios y comerciales, como es el caso de la constitución en 1908 de la Sociedad Anónima Importadora y Exportadora de la Patagonia (en adelante SAlyEP), más conocida como "La Anónima”. Esta gran empresa familiar basó su estrategia de crecimiento económico en una clara expansión de sus actividades, primero en la región patagónica y luego en el conjunto del país, nacionalizándose argentina por motivos diversos en el año 1918, siendo hoy una de las empresas líderes del sector supermercadista nacional. Esta y otras inversiones han permanecido hasta la actualidad en manos del mismo grupo familiar, lo cual es altamente demostrativo de su capacidad de adaptación para la reproducción del patrimonio y el manejo de las sucesiones generacionales a lo largo de más de un siglo de existencia.

En términos conceptuales, y atendiendo a la complejidad que implica la adopción de una definición universal para este tipo de emprendimientos según las distinciones que los especialistas realizan entre empresa familiar, grupo familiar y familia empresaria (Fernández-Pérez \& Lluch, 2015), se ha adoptado el criterio flexible de Barbero y Lluch que definen a las empresas familiares a partir de considerar:

[...] la propiedad estratégica de por lo menos dos miembros de una familia —o de cada una de las familias participantes, en casos de negocios plurifamiliares_; la participación de al menos dos miembros de la familia en el directorio y la presencia de miembros de más de una generación en propiedad y/o gestión dando cuenta de la voluntad de continuidad en el tiempo, [lo cual incluye también] a las empresas gestionadas por su fundador que se mantuvieron en el tiempo bajo el control de la familia originaria (Barbero \& Lluch, 2015, p. 220).

En este marco, el estudio de los grupos familiares en la historia de las empresas ha gozado en los últimos años de una importante jerarquización, 
producto de una serie de análisis de casos demostrativos de sus reales posibilidades de crecimiento y adaptación en el marco del sistema económico mundial y latinoamericano (Almaraz \& Ramírez, 2018; Dávila, 2015; Fernández-Pérez \& Lluch, 2015; Fernández-Pérez \& Valls, 2017; MartínezEchezárraga, 2015; Monsalve-Zanatti, 2014; Rodríguez-Satizabal, 2014;VidalOlivares, 2015), así como también para el caso argentino. ${ }^{1}$ Investigaciones realizadas en los últimos años han demostrado que el capitalismo argentino, en su cúpula, ha sido y es de base familiar, ${ }^{2}$ al igual que en muchos otros países emergentes.

El carácter originariamente regional de estas empresas nos lleva también a considerar la articulación de alianzas y redes parentales entre un conjunto de familias líderes en una misma zona (Granovetter, 1998), lo cual les habría permitido asegurar la sucesión generacional en una suerte de "tejido empresarial", tal y como lo define Cerutti $(2015$, p. 154) para el caso mexicano, que prevalece en dicho espacio económico hasta la actualidad, a la vez que se proyecta y se extiende al ámbito nacional, facilitando la posibilidad de su permanencia y perdurabilidad intergeneracional.

A lo anterior sumamos una aproximación inicial a las diversas actividades que permitieron sostener la primera fase de acumulación, así como a la genealogía y composición de las familias en el área estudiada (Bandieri, 2015; Bandieri \& Almaraz, 2020). Las relaciones políticas y económicas con los poderes regionales y nacionales, así como los intereses afines con compañías y potencias extranjeras, habrían garantizado el desarrollo y la perdurabilidad de los negocios de los empresarios magallánicos (Bascopé, 2008; Harambour, 2017).

En esta presentación se retomará el análisis de las estrategias económicas de estos grupos familiares y de su amplia gama inicial de inversiones diversificadas, con especial atención a la ocupación de tierras para la actividad ganadera, a la operación de los primeros frigoríficos ovinos, a sus actividades bursátiles y financieras y a su participación en diversos emprendimientos empresariales independientes -líneas aéreas, navegación, servicios de telecomunicaciones, empresas editoriales, entre otras-, para avanzar luego en el análisis específico del desenvolvimiento de la firma y

1 Véanse, entre otros, los trabajos realizados sobre distintos grupos familiares en Argentina: Bunge y Born (Schvarzer, 1989); Tornquist (Gilbert, 2003; 2009); Bemberg (López-López, 2011); Avellaneda y Terán (Moyano, 2015).

2 Entre 1918 y 2010 las firmas familiares habrían superado a las no familiares dentro de las mayores empresas argentinas, con porcentajes de participación que oscilaron entre 60 y 80 \% (Barbero \& Lluch, 2015). 
sus estrategias económicas en los últimos años, con el objeto de explicar su exitoso posicionamiento actual en el sector supermercadista nacional. Como podrá verse, el caso de la SAlyEP resulta también paradigmático con respecto al éxito de este tipo de conductas empresariales de carácter familiar en el país.

\section{EL ESCENARIO}

La Patagonia ha sido frecuentemente considerada como sinónimo de "desierto", tanto en sus aspectos físicos como sociales. Sus extendidas mesetas centrales y la rigurosidad de su clima admiten casi exclusivamente la crianza de ganado ovino en estancias de grandes extensiones, particularmente importantes en su sector más austral. Socialmente, la preexistente ocupación del área por sociedades indígenas, carentes de "civilización" para las dirigencias nacionales, motivaron su exterminio e incentivaron su reemplazo por poblaciones extranjeras.

Por otra parte, y hasta hace no muchos años, los estudios de historia económica argentina afirmaban que el conjunto de los territorios patagónicos se había incorporado al sistema económico nacional e internacional con exclusiva orientación atlántica a través de la producción de ganado ovino, desplazado de la llanura pampeana por el auge de los cereales y la crianza de vacunos. Esta afirmación, altamente generalizadora, debe hoy relativizarse a la luz de una cantidad importante de investigaciones, producidas tanto en Chile como en Argentina, que demuestran la expansión de sectores económicos del área del Pacífico hacia la Patagonia argentina al menos hasta las décadas de 1930 y 1940 (Bandieri, 2005).

En el caso que nos ocupa, tempranamente se marcó la existencia de una región autárquica ${ }^{3}$ conformada por las áreas de Santa Cruz y Tierra del Fuego, cuya economía habría dependido casi exclusivamente del área chilena de Magallanes, particularmente en lo referido a la provisión de lanas y carnes ovinas para su comercialización, siendo un escaso número de familias empresarias los actores primordiales de este proceso. Nuevas investigaciones obligan a relativizar la noción de autarquía. Si bien resulta evidente el dominio de aquellos grupos de negocios vinculados a la dinámica

3 La denominación de región autárquica fue utilizada originariamente por reconocidos autores de Punta Arenas (Martinic, 1975, 1976, 2005) y de Santa Cruz (Barbería, 1992, 1996). 
económica del estrecho que reinvirtieron sus excedentes en la Patagonia austral, no habría existido un desarrollo capitalista independiente, como bien demuestran Salvaj et al. (2017) en lo que denominan el "clúster magallánico". Por el contrario, resultan probadas las significativas relaciones políticas y económicas con los poderes locales y nacionales, los consulados extranjeros y las grandes compañías de origen londinense-malvinero o alemán, que permitieron que sus respectivos imperios compartieran, y por momentos disputaran, no sin importantes actos de corrupción (Harambour, 2017), el acceso a la tierra, la producción y el comercio de lanas y carnes, el crédito de bancos y aseguradoras, el comercio y el transporte (figura 1).

Recuérdese que Punta Arenas era por entonces el punto más dinámico del sur chileno, por su estratégica posición dominante en la comunicación interoceánica, mientras que un gran vacío productivo y demográfico caracterizaba al área comprendida entre Puerto Montt y la región magallánica - las tierras de entremedio, como se conocían entonces-, de intrincada geografía. Ello facilitó que la influencia de esta localidad se consolidara en el área sur del continente, proveyendo de lana y carne ovina congelada a los mercados europeos a través de su puerto y de su industria frigorífica. Sobre finales de 1910 puede ubicarse el momento de mayor auge de esta actividad, cuando la provisión de ovinos argentinos constituía hasta el 50 $\%$ de los animales sacrificados con destino a los mercados de ultramar. ${ }^{4}$ Esta dinámica de funcionamiento regional, aunque debilitada a causa de la pérdida del monopolio de la comunicación interoceánica del estrecho de Magallanes por la apertura del canal de Panamá en 1914, las consecuencias de la Primera Guerra Mundial y la implantación de impuestos aduaneros por parte del Gobierno argentino, habría seguido siendo importante hasta la crisis internacional de la década de 1930, cuando la hegemonía histórica de Punta Arenas se debilitó notoriamente, cortándose definitivamente luego de 1943, en el momento en que los respectivos Estados nacionales acentuaron sus rumbos diferentes y muchas veces competitivos (Martinic, 2005). 
TIEMPO \& ECONOMÍA

Figura 1. Expansión económica magallánica (1885-1920)

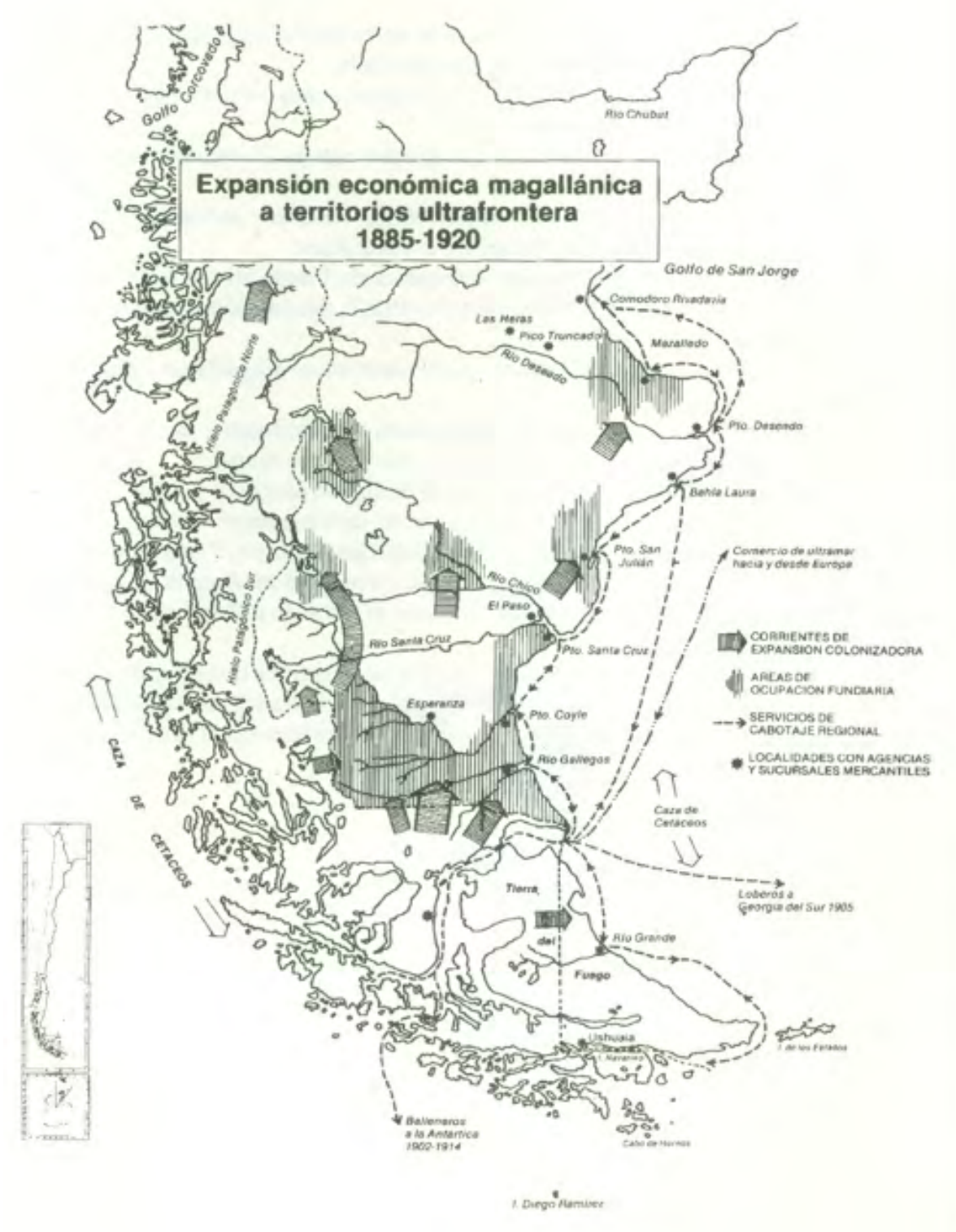

\section{EL ACCESO A LA TIERRA}

Entre 1879 y 1885 el Estado argentino encaró de manera definitiva la extensión de su soberanía a los territorios hasta entonces ocupados por sociedades indígenas a través de una serie de campañas militares y de acciones civiles de los nuevos propietarios que provocaron en algunas áreas su 
total exterminio, particularmente en el caso de aquellos que habitaban la zona más austral de la Patagonia (Chapman, 1983).

En 1884, con la sanción de la Ley 1532, la antigua Gobernación de la Patagonia se dividió en diversos Territorios Nacionales, entre ellos los de Santa Cruz y Tierra del Fuego, estableciendo sus superficies, límites y formas de administración. Hasta mediados de la década de 1950, momento en que se convirtieron en provincias - con la sola excepción de Tierra del Fuego, que lo hizo en 1990-, estos territorios fueron simples divisiones administrativas carentes de autonomía y dependientes del Gobierno central, que designaba a sus gobernantes y administraba sus recursos.

Las posibilidades productivas de la zona para la crianza de ovinos introducidos primeramente desde Malvinas - eran ya conocidas, y para fines del siglo XIX el número de animales había crecido considerablemente, lo cual incrementó la presencia de importantes inversionistas extranjeros en la región.

En ese marco se implementaron una serie de medidas para la distribución de las tierras expropiadas a las sociedades indígenas, en condiciones muy favorables para los nuevos propietarios (Bandieri, 2005a, 2018). En la década de 1890, con el objeto de activar la formación de un mercado de tierras patagónico, el Estado argentino comenzó una intensa campaña de venta de predios, con importante propaganda en Europa. A esos fines se sancionó, en 1894, la Ley Especial 3053, que aprobaba el contrato firmado entre el presidente Carlos Pellegrini y el prestamista alemán Adolfo Grünbein (Ministerio de Agricultura, 1901). Por este acuerdo, el Gobierno vendía en forma directa, con inmejorables condiciones para el comprador, una superficie de un millón de hectáreas a elección del interesado en los territorios de Chubut y Santa Cruz, aunque la medida solo afectó a este último. Los argumentos utilizados sostenían que las tierras vendidas eran de calidad inferior - aun cuando todavía no se habían explorado ni mensurado-, siendo por lo tanto una operación muy beneficiosa en precio y resultados para su beneficiario. Casado con Sofía Seeber, y por esa vía emparentado con importantes políticos y grandes capitales porteños, Grünbein era gestor de una sociedad alemana creada en 1886 - Sociedad Augusto Link y Cía., dedicada al comercio de exportación e importación-y del Banco de Amberes. Asesorado por dos estancieros malvinenses instalados en Santa Cruz - Juan Hamilton y Tomás Saunders-, a cambio de tierras y de un porcentaje sobre las ventas, se concretó este verdadero negociado. El Gobierno 
nacional suspendió todo trámite de entrega de tierras en Santa Cruz entre 1892 y 1895 hasta tanto Grünbein eligiera los lotes a ocupar. Finalmente, estas superficies fueron distribuidas entre 21 propietarios, 14 de los cuales poseían ya grandes empresas ganaderas instaladas en Chile y Santa Cruz, quienes aprovecharon la oportunidad para ampliar sus propiedades, a la vez que el grupo inversor obtenía significativas ganancias.

También Carlos María Moyano, gobernador del Territorio Nacional de Santa Cruz entre los años 1884 y 1887, contribuyó a este proceso. Este funcionario, que había ocupado cargos importantes en la Armada Nacional, siendo también director de la Oficina de Límites, sirvió de intermediario para el arrendamiento o compra de tierras públicas en la Patagonia. ${ }^{5}$ Con posterioridad a la firma del tratado limítrofe con Chile en 1881, facilitó el acceso a la tierra de importantes grupos económicos de Punta Arenas. En 1885, un decreto del presidente Roca le confirió amplias facultades para otorgar tierras de pastoreo a los malvinenses que quisieran poblar el área continental, lo que abrió las puertas a gran parte de los productores ovinos de origen británico que ocuparon terrenos en el sur y centro de Santa Cruz, como los grupos Waldron, Wood y Greenhilds, entre otros (Coronato, 2018).

De igual forma, entre 1876 y 1884, el Gobierno chileno fomentó la entrega de tierras fiscales en el sector norte de la isla de Tierra del Fuego, primero a título precario y luego mediante subastas entre los mismos beneficiarios, con el objeto de avanzar en la ocupación productiva de las zonas limítrofes discutidas con Argentina. Sobre mediados de la década de 1880 se contabilizaban en el área 20 explotaciones rurales con más de 40.000 cabezas de ganado. Fueron favorecidos por estas entregas algunos empresarios malvinenses, como los Hamilton, Saunders, Hyle y Ness, además de Nogueira y Menéndez, comerciantes ya instalados en Punta Arenas. Nogueira obtuvo de esta manera una superficie de 180.000 hectáreas en el sector chileno de la isla, y Mauricio Braun otras 170.000 (Lafuente, 2015).

En síntesis, el acceso a la tierra, bajo formas de propiedad y arrendamiento muy beneficiosas, fue la primera y principal estrategia de estos grupos en su proceso de acumulación, favorecido por las políticas que a ese respecto tomaron ambos Estados nacionales. ${ }^{6}$

5 Con respecto a los arrendamientos, la oferta de Moyano consistía en el otorgamiento de hasta 40 mil hectáreas mediante un pago de 20 pesos en moneda nacional argentina por año (Lafuente, 2015).

6 Para el caso chileno, véase Bascopé (2008) y Harambour (2017). 


\section{DE PEQUEÑAS EMPRESAS FAMILIARES A GRAN FAMILIA DE EMPRESAS}

De Punta Arenas provendría entonces una de las más tempranas iniciativas de ocupación económica del área más austral de la Patagonia argentina por parte de hombres de negocios - no necesariamente con capital inicial-, como es el caso de José Nogueira, ${ }^{7}$ quien concentró sobre las últimas décadas del siglo XIX una serie de actividades económicas propias de la región, como la casa de lobos marinos, el rescate de cargas naufragadas (raques), la explotación de oro, el comercio y el cabotaje regional, siendo además agente de la Compagnie Maritime du Pacific. En 1886 se asoció con Gastón Blanchard, apoderado de una firma francesa en Valparaíso, para la realización de actividades comerciales, de agencias de seguros y de navegación de cabotaje y de ultramar, realizando un activo intercambio de importación y exportación a través de los puertos de Montevideo, en Uruguay, y de Valparaíso, en Chile.

José Nogueira pronto se vincularía con Elías Braun, ${ }^{8}$ conformando una compañía exportadora de cueros de lobos marinos, lanas y plumas de avestruz, iniciándose como ganaderos en la Patagonia a partir de 1889, luego de la obtención de dos concesiones de tierras compartidas, dando lugar a la formación de la Compañía de Haciendas de Oveja de Tierra del Fuego (luego Sociedad Explotadora de Tierra del Fuego), dueña para 1900 de 1,7 millones de hectáreas y de 12 millones de ovinos en campos ubicados a uno y otro lado del estrecho y de la frontera internacional.

Con tan solo 15 años, Mauricio Braun, hijo de Elías, ${ }^{9}$ trabajó como empleado en las oficinas de José Nogueira, convirtiéndose más tarde en su cuñado -y también su socio en el negocio de las loberías-, cuando este contrajo matrimonio con su hermana, Sara Braun, en 1887. Mauricio, por

7 José Nogueira (1845-1893), de origen rural muy humilde, nació en un pequeño pueblo portugués. Las graves crisis económicas lo obligaron a embarcarse como grumete en un barco mercante a los 12 años de edad. Luego de estancias diversas en Brasil, Perú y Uruguay, llegó a Buenos Aires en 1864 y, dos años después, se estableció para probar suerte en Punta Arenas, con solo 21 años, sin capital, familia, ni instrucción alguna (Lafuente, 2015).

8 Elías Braun y su esposa, Sofía Hamburger, habían nacido en 1862 y 1865, respectivamente, en Telsen, parte entonces del imperio ruso (hoy República de Letonia). De origen judío, sufrieron la persecución zarista, migrando primero a Hamburgo, luego a Londres y después a otros sitios de Sudamérica, para llegar finalmente a Buenos Aires a comienzos de la década de 1870. En esta ciudad, un diplomático chileno ofrecía tierras y bienes básicos a colonos europeos que quisieran instalarse en el sur del país, recibiendo 24 hectáreas, más 12 adicionales por cada hijo mayor de 14 años, así como materiales para la construcción de una vivienda, una vaca, una yegua y alimentos para los primeros seis meses, lo que llevó a la familia a instalarse en Punta Arenas (Lafuente, 2015).

9 Sara, Mauricio y Óscar nacieron en Telsen, Ana en Paraguay, y los tres hijos menores, Fanny, Mayer y Juan, en Punta Arenas. 
su parte, contraería matrimonio en 1895 con Josefina, hija mayor de José Menéndez y María Behety. ${ }^{10}$

A José Menéndez, ${ }^{11}$ asturiano de origen, ya se lo ubica en Buenos Aires en 1866 como tenedor de libros en un negocio de ferretería. En 1873 contrajo matrimonio con María Behety, nacida en Montevideo. Sus primeros descendientes, Josefina y Alejandro, nacieron en Buenos Aires, mientras que el resto lo hizo en Punta Arenas, ciudad a donde se dirigió a cobrar una deuda a José Piedra Buena, conocido marino de Carmen de Patagones, propietario de una casa de ramos generales que Menéndez finalmente le adquiriría (Lafuente, 2015). El matrimonio de sus hijas e hijos con reconocidos miembros de la sociedad local, regional y nacional aumentó su inserción y la posibilidad de ampliar la red de negocios familiares, ${ }^{12}$ dando cuenta de la importancia de las alianzas sociales y familiares para la reproducción del patrimonio y el incremento de los vínculos políticos. Tales relaciones permitieron a Menéndez fomentar la radicación de una colonia de asturianos en Punta Arenas dedicados a los negocios productivos y comerciales, entre ellos José Montes Pella.

De estos primeros grupos se desprendieron luego otras firmas regionales con intereses diversos en Tierra del Fuego y Santa Cruz, como la sociedad de Mauricio y Sara Braun, esposa de Nogueira, Blanchard y Nogueira (luego Braun-Blanchard) y, con la incorporación de José Menéndez, la SAlyEP.

10 Mauricio Braun falleció en Buenos Aires en 1953. Tuvo con Josefina Menéndez Behety diez hijos, que se dedicaron mayoritariamente a las actividades ganaderas y comerciales, contrayendo matrimonio con descendientes de importantes familias de la época: Carlos, casado con Emilia Agote; Alejandro, con María Esther Campos Menéndez; Armando, con María Estrugamou; Eduardo, con María Teresa Cantilo; Oscar, con María Seeber, hermana de la esposa de Grünbein; Laura, soltera; Josefina, con Juan J. Caminos Hayward, integrante de la firma Caminos y von Peeborgh, dedicada a la exportación de lana; María Sofía, casada con su primo Francisco Campos Menéndez; Ricardo, con Mercedes Lasala, y Mauricio, casado con Anita Bidau (grupo familiar de Mauricio Braun-Hamburger; https://genealogiafamiliar.net/old/familygrup.php?family/ YID=F65628tree=BVCZ).

11 José Menéndez (1846-1918) nació en el pequeño pueblo de Santo Domingo de Miranda, en tierras asturianas. De origen rural y padre jornalero, las graves condiciones económicas del lugar lo obligaron a los 14 años a partir rumbo a La Habana y luego hacia Buenos Aires.

12 Al casamiento de la hija mayor de Menéndez, Josefina, con Mauricio Braun, se sumaron luego los matrimonios de José con Teresa Montes Thuler, María con Francisco Campos Torreblanca, Carlos con Cristina García González Bonorino, Julio con Graciela Prendes y Herminia con Arturo Gómez Palmés, todos ellos participantes muy activos en las sociedades familiares (grupo familiar de Mauricio Braun-Hamburger; https://genealogiafamiliar.net/old/familygrup.php?family/ YID=F65628tree=BVCZ). 


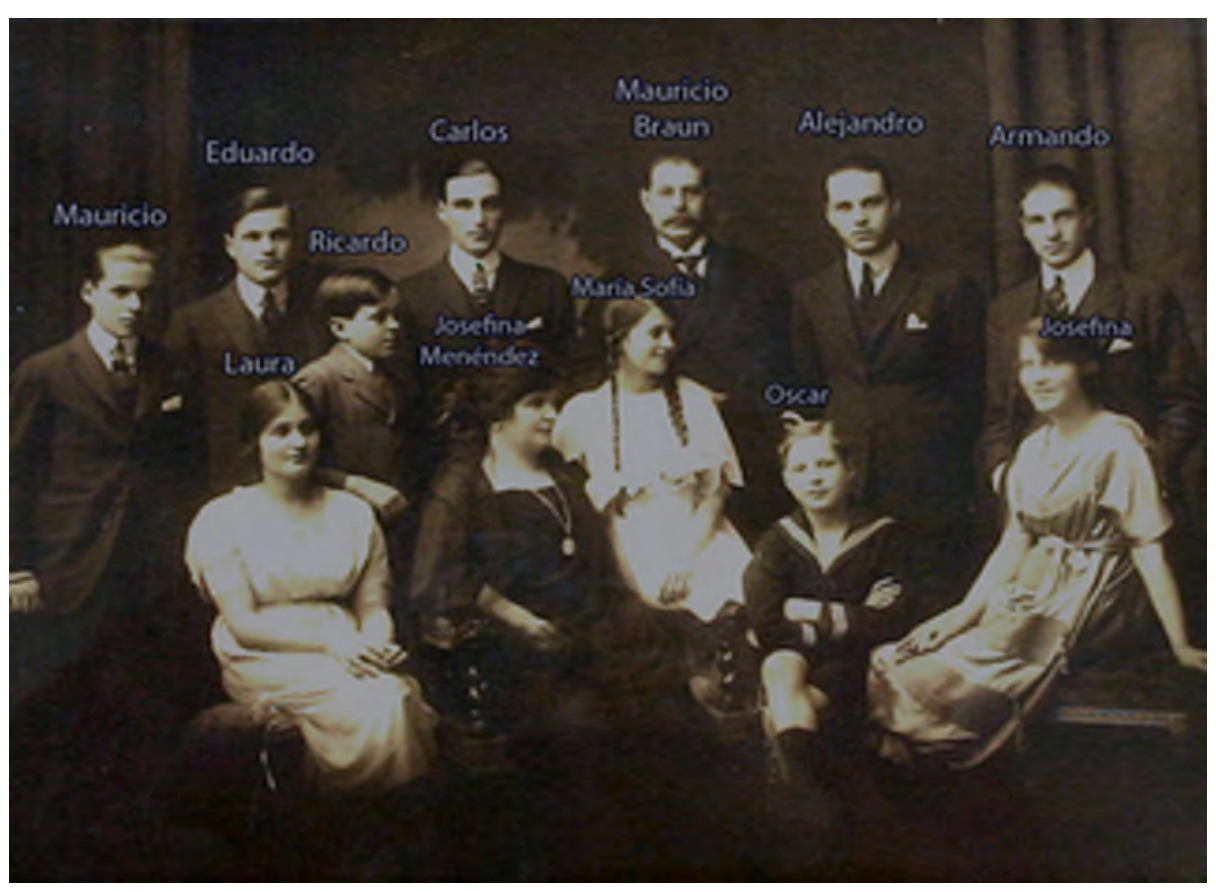

Figura 2. Familia Braun-

Menéndez Behety (1920)

Fuente: tomada de https://

www.museodemagallanes.gob. cl/645/w3-article-48586.html?_ noredirect $=1$.

\section{LA DIVERSIFICACIÓN COMO ESTRATEGIA}

Mauricio Braun, ya como socio de Nogueira, expandió sus actividades hacia el comercio marítimo, trasladando ovinos desde Malvinas al sur patagónico. En 1892, ampliados sus negocios al cabotaje regional de todo tipo de mercancías, se asoció con Juan Blanchard, ${ }^{13}$ sobrino de Gastón, para ser representantes de las más importantes compañías navieras de ultramar.

Punta Arenas era por entonces una pequeña colonia de pocos habitantes, entre funcionarios, militares, convictos y unos pocos civiles. En la medida en que el estrecho de Magallanes se consolidaba como ruta interoceánica, las actividades económicas también se diversificaban, impulsadas por la existencia de arenas auríferas, de explotación muy exigua y por la importancia del cabotaje regional. En tanto la ciudad crecía, las necesidades de materiales para la construcción de viviendas se hacían mayores, generando la instalación de importantes aserraderos. Para mediados de la década de 1870, Punta Arenas ya alcanzaba los 800 pobladores; pocos años después, en 1885, superaba 2.000 habitantes y en 1907 los 13.000 (Martinic, 2005).

13 Juan Blanchard dejó su Francia natal a los 19 años para radicarse en Punta Arenas. Falleció en Valparaíso en 1955. 
A partir de 1881, cuando concluyeron temporalmente los desacuerdos limítrofes entre ambos países, las relaciones regionales se intensificaron, conformándose una serie de sociedades ganaderas, muchas de ellas con sede fiscal en Valparaíso, que cotizaban en bolsa y emitían acciones a los efectos de financiar los emprendimientos. En la búsqueda de socios para la explotación de las superficies obtenidas, Nogueira acordó en 1890 con Waldron y Wood, grupo empresario londinense-malvinense, la formación de la sociedad The Tierra del Fuego Farming Company, radicada en Londres. En junio del mismo año se le concedieron 1.009.000 hectáreas más en la parte chilena de la isla y la empresa pasó a ser la Sociedad Explotadora de Tierra del Fuego. Otros empresarios magallánicos recibieron, como parte de la entrega de tierras públicas que hiciera el gobernador Moyano, superficies importantes en el área argentina de la Patagonia, que superaron las 300.000 hectáreas, donde se conformaron una serie de importantes estancias.

Con el fallecimiento de José Nogueira en 1893 - quien no alcanzó a hacerse de superficies del lado argentino del continente-, coincidió un nuevo litigio limítrofe entre ambos países, solucionado pacíficamente a comienzos de siglo con el encuentro de sus presidentes, Roca y Errázuriz, en la ciudad de Punta Arenas. A partir de allí se amplió la participación de los empresarios magallánicos, quienes se transformaron en propietarios o arrendatarios de tierras fiscales en la parte argentina de la isla de Tierra del Fuego y en Santa Cruz, contando para ello con varios intermediarios en la ciudad de Buenos Aires, entre ellos el exgobernador Moyano. Para facilitar tales asentamientos, el presidente Roca dispuso el tendido de la línea telegráfica entre Cabo Vírgenes y Punta Arenas, en tanto que el Gobierno chileno eliminó todo tipo de impuestos aduaneros. Coincidentemente con ello, también se amplió la participación de Mauricio y Sara Braun en las sociedades antes constituidas por Nogueira, así como también la de José Menéndez y varios políticos y funcionarios chilenos. Con sede en Londres, la Sociedad Explotadora se convertiría en la mayor concentración de superficies en la isla (1,7 millones de hectáreas) y en Santa Cruz (100.000 hectáreas). Un año antes del fallecimiento de José Nogueira, en 1892, se había producido el de Gastón Blanchard. Mauricio Braun decidió entonces comprar, con su sobrino Juan Blanchard, la Sociedad Naviera y Comercial Nogueira y Blanchard, para más tarde, en 1908, dar origen a la SAlyEP. La nueva sociedad incursionó en emprendimientos varios, como astilleros, navegación comercial, seguros, empresas telefónicas $y$, fundamentalmente, actividades comerciales 
y crediticias. Por su parte, el rubro ganadero se manejó con sociedades independientes, aunque integradas por los mismos socios.

Además de varias estancias establecidas en el sector chileno de la isla de Tierra del Fuego mediante la constitución de diversas sociedades, como la Sociedad Ganadera Braun, Martínez y Cía., integrada también por Juan Blanchard, la Sociedad Estancias "La Armonía”, de Sara Braun de Valenzuela, ${ }^{14}$ Alejandro y José Menéndez Behety y Casimiro Gómez, ${ }^{15}$ y la Sociedad Ganadera Sara Braun Ltda., con participación de Elías Braun y sus hijos Mauricio, Oscar, Mayer y Juan, estos grupos mantuvieron e incrementaron sus explotaciones ganaderas en Argentina con la conformación de un número importante de estancias.

Del sur chileno provino también la primera casa bancaria de la Patagonia austral, instalada en Río Gallegos en 1899, filial del Banco de Tarapacá y Londres de Punta Arenas, más tarde absorbido por el Banco de Londres y América del Sur, bajo la conducción de uno de los yernos de Menéndez, Francisco Campos Torreblanca, quien fuera también director fundador de "La Anónima" e integrante del directorio de la Compañía Frigorífica del mismo grupo familiar, con lo cual se vuelven evidentes las vinculaciones existentes entre los capitales ganaderos, industriales, comerciales y financieros de ese origen instalados en la región, como profundizaremos a continuación. También el Banco de Punta Arenas y Magallanes, fundado por Menéndez y Braun a comienzos del siglo XX en esa ciudad, crearía sucursales en Puerto Santa Cruz en 1912, en San Julián en 1916 y en Río Gallegos en 1918, para convertirse, un año después, en el Banco de Chile y la Argentina, con sucursales en ambos países. La temprana expansión empresarial de este grupo puede verse en el cuadro 1.

Según se observa, con una significativa diversificación de sus inversiones, Mauricio Braun incursionó en distintas actividades, entre ellas la industria frigorífica de Punta Arenas, para lo cual se asoció con otros empresarios ganaderos del sur de Chile y de Santa Cruz que comercializaban sus animales en esa ciudad. Prueba de ello es que los caminos que unían las estancias de la región con Punta Arenas y Puerto Natales eran más numerosos

14 Sara Braun, primera mujer empresaria del lugar, se había casado en segundas nupcias en 1914 con el marino chileno Leoncio Valenzuela.

15 Casimiro Gómez, dueño de la talabartería más grande de Buenos Aires, proveedor del Ejército nacional, también obtuvo tierras en otros territorios patagónicos como Neuquén (Blanco, 2007). Cabe destacar que el nombre "La Armonía" que llevaba esta estancia era el de la logia masónica a la que pertenecía Gómez en la capital porteña y, muy posiblemente, también otros miembros de las sociedades constituidas en la Patagonia austral. 
y transitados que los que llevaban a Río Gallegos, en la costa argentina. Su unión matrimonial con Josefina Menéndez Behety y el casamiento de dos de sus hijas con importantes inversionistas de la región, Campos Torreblanca y Caminos, que también se integraron a las empresas de la familia, aumentaron las posibilidades económicas del grupo.

Cuadro 1. Grupo Braun: actividades ganaderas, comerciales, industriales y financieras (1884-1920)

\section{Área marítima}

- 1884: Sociedad Braun-Scott (cabotaje regional).

- 1892: Sociedad Braun-Blanchard (cabotaje, astillero, agencia compañías de ultramar).

- 1907: Empresa naviera transformada en 1929 en la Compañía Chilena de Navegación Interoceánica. Frigoríficos

- Participación en los frigoríicos Río Seco, Río Grande, Puerto Deseado, Puerto Sara, Puerto Bories, Puerto Natales. Área comercial

- 1892: Braun y Blanchard.

- 1908: Sociedad Anónima Importadora y Exportadora de la Patagonia "La Anónima”.

Otras empresas

- 1897: Compañía de Electricidad de Punta Arenas.

- 1900: Banco de Punta Arenas (Chile y Argentina).

- 1904: Sociedad Ballenera de Magallanes; Compañía Minera Cutter Cove.

- 1915: Compañía de Seguros La Austral.

- 1918: Compañía Telefónica de Magallanes.

- 1923: S. A. Explotadora de las Termas Villavicencio. Área ganadera

- Sociedad Ganadera Argentina; Sociedad Pastoril Glencross, Santa Cruz; Sociedad Estancia Santa Cruz; Southern Patagonia Sheep Farming Company; Compañía Exportadora Cerro Palique; Sociedad Explotadora de Tierra del Fuego; Sindicato San Julián; Sociedad Industrial de Puerto Aysen; The San Julián Sheep Farming Company; Sociedad Estancias Lago Posadas; Sociedad Ganadera Valle Huemules; Sociedad Estancia Los Manantiales.

- Estancias en Santa Cruz: "Coy Aike"; "Monte Negro"; "Los Machos"; "Tcheon-Aike"; "Sofía”;"Cerro Comisión”.

- Participación en las estancias: "La Maciega”; "Tapi-Aike"; "María Inés"; "San Elías"; "Vidalita”; "Cancha Rayada"; "La Federica"; "El Librún"; "Coluhuel-Aike"; "San Mauricio"; "La Flora"; "La Carlota".

- Estancias en Chubut:"Quichaura"; "Pepita"; "Laura"; "Laurita”.

Entre sus propios establecimientos ganaderos, los conformados en sociedad con otras personas y los pertenecientes a grandes compañías en las que aparecía como accionista, Mauricio Braun se convirtió en el más importante latifundista de la región. Según sus propias declaraciones, en el año 1931 había llegado a reunir como propias más de 1,6 millones de hectáreas, ocupando de hecho otras 490.000. Participaba además, en calidad de accionista importante, en 9 compañías ganaderas, entre las que sobresalían: Southern Patagonia Shepp Farming Company, Sociedad Cerro Palique, 
Sociedad Anónima Ganadera y Comercial Sara Braun y The San Julian Shepp Farming Company. ${ }^{16}$

De estas compañías, la Southern Patagonia Shepp Farming, de algo más de 170.000 hectáreas, tuvo su origen en la Sociedad Estancia Santa Cruz, constituida en Valparaíso en 1910 y conformada originalmente por Mauricio Braun, José Menéndez y otros. En la nueva sociedad se integraron, además, Sara Braun, la Sociedad Braun-Blanchard y la casa comercial británica Duncan Fox. La Sociedad Anónima Ganadera y Comercial Sara Braun, cuyo presidente también era Mauricio Braun, obtuvo a título de propiedad más de 260.000 hectáreas en Santa Cruz mediante la Ley de Remate Público de 1882 y por compra a terceros, en excelentes zonas cercanas a Río Gallegos. Por último, la The San Julian Shepp Farming Company contó con Mauricio Braun como principal accionista, alcanzando 221.000 hectáreas. En Tierra del Fuego también accedió a la concesión de una importante superficie de tierras al sur y norte del río Grande, constituyendo en 1899 las estancias "Primera Argentina" (luego "José Menéndez") y "Segunda Argentina". Por desmembramiento de esta última se constituyó la estancia María Behety, de más de 60.000 hectáreas, uno de los más importantes y modernos establecimientos ovejeros del área fueguina. ${ }^{17}$

De los negocios iniciales de José Menéndez se desprendió la Sociedad Anónima Ganadera Argentina Menéndez-Behety, propietaria de 368.000 hectáreas, además de empresas comerciales, frigoríficas, de telecomunicaciones y de energía eléctrica, ubicadas en distintos puntos de Tierra del Fuego, Chubut y Santa Cruz, con sede también en Punta Arenas, como la Sociedad Anónima Ganadera Comercial Menéndez-Behety, donde agregaba a los rubros ya señalados la propiedad de aserraderos y empresas de navegación. Entre los establecimientos ganaderos a nombre del grupo o de alguno de sus integrantes, más la participación en otras sociedades, llegó a tener a comienzos del siglo XX, más de 660.000 hectáreas (cuadro 2). 
Cuadro 2. Grupo MenéndezBehety: actividades ganaderas, comerciales industriales y financieras (1876-1920)

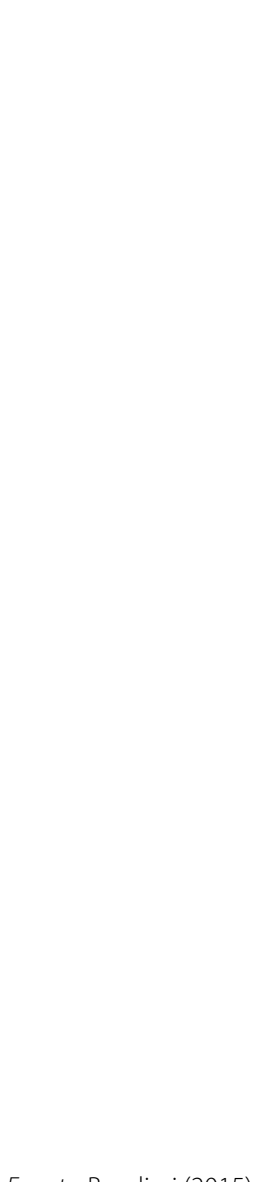

Fuente: Bandieri (2015).

\section{Actividades iniciales de José Menéndez}

1876- Comercio, ramos generales.

1878- Caza de lobos marinos; ganadería; rescate de naufragios.

1879- Comercio de pieles y plumas de avestruz.

1880- Hotelería; aserradero.

1881- Minería aurífera.

\section{Sociedad Anónima Ganadera Argentina Menéndez Behety}

- Compañía Frigorífica Argentina de Tierra de Fuego (Río Grande).

- Sociedad Cooperativa Frigorífica de Puerto Deseado.

- Sociedad Anónima Importadora y Exportadora de la Patagonia "La Anónima".

- Sociedad Anónima Ganadera "Nueva Oriental” (Chubut y Santa Cruz).

- Sociedad Estancia Santa Cruz.

- Sociedad Anónima Ganadera "Valle Huemules” (Chubut).

- Sociedad Anónima Ganadera “Los Lagos".

- Compañía de Alumbrado Eléctrico de Río Gallegos.

- Compañía de Alumbrado Eléctrico Santa Cruz (Puerto Santa Cruz).

- Compañía de Alumbrado Eléctrico Chubut (Trelew).

- Empresa Telefónica del Sur (Comodoro Rivadavia).

Sociedad Anónima Ganadera Comercial Menéndez Behety (Punta Arenas)

- Sección Comercial.

- Sección Marítima.

- Sección Aserraderos (Magallanes y Tierra del Fuego).

- Compañía Frigorífica de Patagonia, Frigorífico en San Gregorio.

- Sociedad Industrial y Ganadera de Magallanes.

- Compañía de Electricidad de Punta Arenas.

- Compañía Telefónica de Magallanes.

- Compañía de Seguros "La Austral".

Estas importantes empresas familiares, consolidadas a través de uniones parentales, son un claro ejemplo de las posibilidades de diversificación de capital que permitía el área patagónica con las conexiones debidas. Estos grupos societarios manejaron además el monopolio de los negocios de importación y exportación ejercidos a través de "La Anónima", constituida en 1908, que se convirtió en prestamista y acreedora de las demás empresas regionales.

En cuanto a la concentración en propiedad o arrendamiento de tierras de ambos grupos familiares en la Patagonia austral, puede observarse su magnitud hacia 1920, cuando superaba las 1,5 millones de hectáreas. A ello debe sumarse el arrendamiento de una muy significativa superficie de 
campos fiscales (1.557.000 hectáreas), todos ellos con una importante receptividad ganadera. ${ }^{18}$

\section{LA SOCIEDAD ANÓNIMA IMPORTADORA Y EXPORTADORA DE LA PATAGONIA}

Como ya se dijo, "La Anónima” (en adelante LA) surgió en 1908 a partir de la fusión de los establecimientos comerciales que las firmas José Menéndez-Braun y Blanchard ya poseían en la Patagonia austral. ${ }^{19}$ Con un capital inicial de 1.500 .000 pesos en moneda nacional argentina, de los cuales 1.200.000 fueron aportados en partes iguales por ambas firmas, de cuyos activos y pasivos se hizo cargo la nueva sociedad, incluyendo mercaderías, propiedades y créditos, se convino que los 300.000 pesos restantes fueran integrados por disposición del directorio a partir de la venta de acciones, a 500 pesos cada una, las cuales serían nominales y destinadas con especial preferencia a los accionistas ya existentes, estrategia sin duda importante a la hora de controlar el capital de la empresa.

Un prolijo inventario y balance general de todas las casas comerciales se hizo en esa oportunidad, decidiéndose que la empresa tuviera su sede central en la ciudad de Punta Arenas. A los fines correspondientes, se conformó un directorio con tres directores propietarios (presidente José Menéndez, vicepresidente Mauricio Braun y director Juan Blanchard), dos directores suplentes (Alejandro Menéndez Behety, hijo de José, y Pablo Dietert), un síndico titular (Carlos Menéndez Behety) y un síndico suplente (Guillermo Perkins). Además, como gerente general se desempeñó Esteban Ferrari. ${ }^{20}$ Cómo podrá observarse en la composición de los sucesivos directorios, existió una clara fusión de este grupo empresarial con otros ganaderos y comerciantes del entorno regional, lo cual aseguraba la cohesión de intereses, fortalecida por numerosos lazos familiares. Por otra parte, los apellidos de los miembros se repiten, mientras que el rol de la sindicatura titular, en tanto auditora de la gestión de la empresa, quedó siempre en manos de un miembro de la familia, lo cual permite aportar evidencias en el

\footnotetext{
Biblioteca MECON, Informe de la Dirección General de Tierras y Colonias, 1920.

19 José Menéndez tenía casas comerciales en Río Gallegos, Santa Cruz y Comodoro Rivadavia, abastecidas por su propia flota de ocho barcos; Braun y Blanchard las tenían en Río Gallegos, Santa Cruz, San Julián, Madryn, Trelew y Ñorquinco, con seis barcos propios. 
sentido de lo mencionado por Lluch et al. (2017) sobre la importancia de las estrategias de selección de los síndicos y su contribución en las redes corporativas, así como sobre los usos históricos de esta función como mecanismo de gobernanza de las empresas.

Las primeras sucursales de LA se establecieron en los puertos atlánticos (Río Gallegos, Santa Cruz, San Julián, Comodoro Rivadavia y Puerto Madryn), iniciándose desde allí la progresiva penetración hacia el interior patagónico, con numerosas sucursales donde se recibía la lana de las estancias a la vez que se aseguraba el suministro de víveres, materiales de construcción y elementos diversos para la producción, en tanto que su sección marítima permitía la distribución de cargas. Las ganancias obtenidas en los primeros años son claramente indicativas del éxito comercial alcanzado por la empresa. ${ }^{21} \mathrm{Hacia}$ el final de la Primera Guerra Mundial contaba con treinta establecimientos comerciales en el sur de la Patagonia argentina, entre casas matrices y filiales, funcionando bajo una dirección centralizada pero con autonomía importante de las sucursales, lo cual permitía tomar las decisiones más inmediatas que las distancias y la falta de comunicaciones dificultaban.

Cabe recordar que la guerra representó para la zona una importante oportunidad económica debido al incremento en la demanda de lana en el mercado internacional, lo cual aumentó las posibilidades de expansión de la actividad, así como de los servicios navieros y comerciales, en tanto que la población del área, tanto argentina como chilena, mostraba un sostenido aumento. Durante los últimos años de la guerra los precios de la lana mantuvieron un crecimiento constante, provocando una acumulación especulativa de stocks por parte de los grandes productores patagónicos, así como un endeudamiento confiado con bancos y comerciantes ante la presunta perdurabilidad de la situación. La etapa de prosperidad de la economía lanera atrajo por su parte a trabajadores del resto del país, en tanto que nuevos contingentes de inmigrantes llegaron de la Europa de postguerra, donde la marcha de las revoluciones sociales pareció augurar una más floreciente situación del proletariado. Los establecimientos ovinos se generalizaron en toda la Patagonia, ocupando también las tierras fiscales del interior, antes desechadas.

21 En el primer ejercicio comercial al 30 de junio de 1909, el capital social declarado por LA era de $£ 142.480$, equivalente a $\$ 1.631 .396$ en moneda nacional; en junio de 1910, de $£ 180.000$, equivalente a $\$ 2.061 .000$; en 1912 , de $£ 250.000$, equivalente a $\$ 2.862 .500$; en junio de 1914 , de $£$ 400.000 , equivalente a $\$ 4.580 .000$; en 1919 , de $\$ 11.363 .636$ en moneda nacional, equivalente a 5 millones de oro sellado; en junio de 1920, de $\$ 27.655 .955$ en moneda nacional (Archivo del MRT, Ricardo Fisch, 25 años de actividad económica a través de Memorias y Balances, RAA-SAlyEP, V(49), julio 1933, p. 37). 
Pero en la crisis de posguerra los precios de la lana descendieron, buscando su nivel normal, en tanto que también disminuyó la demanda y las divisas internacionales se reacomodaron, acorde con la renovada recomposición del poder económico de las potencias centrales. Fue entonces cuando la empresa vio cortados los suministros de créditos por parte del Banco de la Nación Argentina y del Banco Anglo-Sudamericano, lo cual a su vez se proyectó en el crédito interno y en el sostenimiento de las ventas "al fiado", como se acostumbraba en la época. La implantación de derechos aduaneros en la Patagonia a finales de 1918 y comienzos de 1919, medida del Gobierno radical resistida fuertemente por los estancieros, produjo una fuerte sacudida de los habituales negocios con las plazas del sur chileno, elevando bruscamente el costo de vida. Los efectos de la crisis se hicieron sentir también en los beneficios percibidos por la empresa. ${ }^{22}$ Por otra parte, la disminución de la demanda incidió en la reducción de los costos y acentuó la explotación de los obreros rurales, en un creciente proceso coadyuvado por la concentración de la propiedad, el monopolio del comercio, el trabajo estacional, las largas distancias y la propia falta de organización de los trabajadores, que no contaban con ningún tipo de protección frente a las condiciones laborales fijadas por los estancieros. El escenario estaba creado para los graves conflictos rurales que se produjeron en la zona a lo largo de la década de 1920, tanto en territorio chileno como argentino, que fueron severamente reprimidos por las fuerzas policiales, a las cuales se unieron los estancieros y comerciantes del lugar (Bayer, 1972).

La nueva situación cambió las perspectivas empresariales. Hasta el año 1918 la firma tuvo su sede central y su abastecimiento de mercaderías en Punta Arenas, aprovechando las conexiones de ese centro portuario con Inglaterra, Alemania, España y otros puntos de ultramar, de donde provenían la mayoría de los artículos que se comercializaban en las treinta sucursales de LA en la Patagonia, además de algunos otros originarios del norte de Chile y de la incipiente industria argentina. Una línea de cabotaje propia permitía a la empresa derivar carnes y lanas a los puertos argentinos y chilenos, con un manejo prácticamente monopólico de los fletes.

22 En el ejercicio comercial con cierre el 30 de junio de 1931 puede evidenciarse cómo las ganancias de la empresa se habían reducido notoriamente a causa de la crisis, alcanzando solo $\$ 15.631 .396$ en moneda nacional. Si bien no es una cifra menor, resulta considerablemente más baja que las consignadas para los períodos anteriores. Por otra parte, los dividendos percibidos por los accionistas, que no bajaron del $10 \%$ en el período 1910-1919, disminuyeron a partir de 1920, para ser en 1928 del 1,5\%, y del 3 y $2 \%$ en los años 1931 y 1932, respectivamente (Archivo del MRT, Ricardo Fisch, 25 años de actividad económica a través de Memorias y Balances, RAA-SAlyEP, V(49), julio 1933, p. 37). 
Para hacer frente a la nueva situación, José Menéndez y Mauricio Braun decidieron realizar nuevas inversiones en Argentina, lo cual implicaba un fuerte cambio en la estrategia empresarial. A esos fines, compraron entre 1915 y 1922 cuatro grandes barcos de carga ("Argentino", "Asturiano", "Americano" $y$ "José Menéndez"), ${ }^{23}$ para dar inicio a una gran empresa naviera y constituir, con el apoyo de los más importantes ganaderos de la región, la S. A. Compañía Frigorífica Argentina de Tierra del Fuego, un moderno frigorífico instalado en el puerto de Río Grande, primero del territorio isleño, utilizando un criterio cooperativo. El directorio de la nueva empresa estuvo presidido por Alejandro Menéndez Behety, siendo su vicepresidente Meyer Braun y sus directores Francisco Campos Torreblanca, Percival Reynolds y José Montes Thuler. Carlos Menéndez Behety ejerció funciones de síndico. Años después, en 1922, se constituyó la S. A. Sociedad Cooperativa Frigorífico de Puerto Deseado, también presidida por Alejandro Menéndez Behety y Mauricio Braun. ${ }^{24}$

Simultáneamente, la SAlyEP instaló una agencia comercial en Buenos Aires para atender los asuntos marítimos y realizar compras. En 1918 se le otorgó personería jurídica, convirtiéndose en una empresa argentina. Muy pronto, los socios propietarios y la dirección general se instalaron en el corazón de la city porteña, lo cual abrió una nueva etapa en la historia de la compañía. A la muerte de José Menéndez, casi simultánea con estos acontecimientos, la nueva sede fue inaugurada por el nuevo director de la firma, Mauricio Braun, siendo su vicepresidente Alejandro Menéndez Behety.

A medida que se superaba la crisis, LA dio muestras de una renovada vitalidad económica. ${ }^{25}$ Con numerosas sucursales en la Patagonia y agentes en países extranjeros, la empresa ofició como consignataria de frutos

23 Sumaron a ello 17 chatas y lanchas, lo cual llegó a representar, para 1940, casi el 5 \% de la Marina Mercante Argentina (Archivo del MRT, s/a, La Marina Mercante Argentina en cifras, RAA-SAlyEP, XX(4), 1956, p. 13).

24 El Gobierno nacional autorizó por ley la instalación del frigorífico de Río Grande en 1917. Con un capital inicial de $\$ 1.200 .000$ en moneda nacional, elevado en 1918 a $\$ 2.400 .000$, se resolvió que todo excedente que superara el $12 \%$ del capital (disminuido luego al $10 \%$ ) sería distribuido entre los productores, accionistas y no accionistas que vendieran sus ovejas al establecimiento. En la primera faena se procesaron casi 150.000 animales. En marzo de 1918 se realizó el primer embarque de 1.000 toneladas de carne con destino a Inglaterra, además de cueros, sebo, tripas y otros subproductos exportados a EE. UU. (Archivo del MRT, s/a, RAA-SAlyEP, I(2), agosto 1929, p. 1).

Para el año 1929, la empresa mostraba un excelente grado de recuperación, con 10 casas comerciales en el territorio de Santa Cruz, 10 en Chubut y 3 en Río Negro, así como agencias en Chile, Nueva York, Barcelona y Berlín, y un capital autorizado de 20 millones de oro sellado (Archivo del MRT, s/a, RAA-SAlyEP, I (2), agosto 1929, p. 2). 
-especialmente lanas y carnes- ${ }^{26}$ transportista y banquera, por cuanto manejaba todo lo concerniente a créditos y anticipos a la producción, convirtiéndose en una activa partícipe en la vida comunitaria de las localidades al colaborar en la instalación de servicios eléctricos, teléfonos, hospitales, escuelas, emisoras de radio, etc. Con una cantidad muy importante de empleados, la sociedad encaró una serie importante de actividades sociales para que sus trabajadores se sintieran parte de una "gran familia", a lo cual unió la publicación de una revista propia entre los años 1929 y 1968, Argentina Austral, utilizada aquí como importante fuente documental. ${ }^{27}$ Así como distintas secciones aseguraron a LA el correcto abastecimiento de sus numerosas sucursales en todos los rubros que hacen a un almacén de ramos generales de gran envergadura, una hábil política crediticia propia le permitió conservar una clientela asegurada. En el año 1935 se incorporó a la firma una Sección de Agencias Interoceánicas, con líneas regulares para el traslado de cargas y pasajeros a distintos continentes.

El 10 de junio de 1933, bajo la dirección de Carlos Menéndez Behety, la empresa festejó sus bodas de plata, evidenciando una importante continuidad en las funciones directivas de sus fundadores, ahora representados por las nuevas generaciones. ${ }^{28}$ Igual estrategia empresarial pudo observarse en 1958, cuando celebró en Buenos Aires su quincuagésimo aniversario, bajo la presidencia de Alejandro Braun Menéndez. ${ }^{29}$ En esta última oportunidad se realizaron homenajes simultáneos a los fundadores fallecidos de la firma, José Menéndez y Juan Blanchard, en Punta Arenas y Viña del Mar, respectivamente, donde habían sido sepultados. Las ramas chilenas de las familias integraron otras compañías, particularmente vinculadas a las actividades marítimas, algunas de las cuales se conservan hasta la actualidad: en el caso de los Blanchard, la Compañía Chilena de Navegación Interoceánica, y en el

También las empresas frigoríficas de Río Grande y Puerto Deseado se consolidaron, sobre todo la primera, con un promedio anual de faenas de 250.000 corderos y una cuota de exportación al mercado inglés de aproximadamente 4000 toneladas en los años subsiguientes, que implicó el sacrificio de más de 5 millones de lanares, con utilidades de aproximadamente 50 millones de pesos moneda nacional para los hacendados. (Archivo del MRT, Juan Jaca, La actividad industrial de D. Alejandro Menéndez Behety, RAA-SAlyEP, XXII(2), 1968, pp. 14-19).

27 Más información sobre esta publicación de la SAlyEP en Ruffini (2017).

28 Ese año, Francisco Campos Torreblanca era su vicepresidente, en tanto Alfonso Menéndez Behety y Alejandro Braun Menéndez eran miembros del directorio. Armando Braun Menéndez ejercía como síndico titular.

29 Francisco Campos Torreblanca ejercía todavía funciones de vicepresidente, en tanto que el directorio estaba integrado por Carlos Braun Menéndez, José Menéndez Montes, Juan Caminos, César Menéndez Behety y Armando Braun Menéndez. Actuaba como director delegado Oscar Braun Menéndez y como síndico suplente Hernando Campos Menéndez; era consejero de zona en la Provincia de Santa Cruz el ganadero Carlos Felton (Archivo del MRT, s/a, Edición Extraordinaria dedicada al Cincuentenario de la firma, RAA-SAlyEP, XXIX(320), 1958, p. 39). 
caso de los Menéndez, la Compañía Marítima de Punta Arenas S. A., claros ejemplos de la diversificación de la inversión en ambos países que mantuvieron los miembros de la sociedad.

Igual homenaje se realizó en Buenos Aires al fallecido Mauricio Braun. Los más destacados hombres de la política, los negocios, las finanzas, la iglesia y las fuerzas armadas de ambos países estuvieron presentes en los actos conmemorativos, dando muestra del alto grado de inserción sociopolítica que habían alcanzado por entonces estos grupos familiares.

Eran entonces épocas de absoluta bonanza. ${ }^{30}$ Con amplio criterio diversificador, en 1957 se creó, junto a otros socios, la empresa Austral Compañía Argentina de Transportes Aéreos, que en 1971 se trasformó en Austral Líneas Aéreas. En 1980 vendieron sus acciones al gobierno de la dictadura argentina, en una operación que ha sido considerada como un verdadero acto de corrupción. ${ }^{31}$ La empresa fue privatizada poco tiempo después, siendo hoy, fusionada con Aerolíneas Argentinas, la primera empresa comercial aérea del país en manos nuevamente del Estado nacional.

También incursionaron con diferentes socios en empresas de diversos rubros, algunas nacionalizadas o desaparecidas en la actualidad, tales como Astilleros Argentinos Río de La Plata S. A. (ASTARSA), en el área de construcciones navales, ferroviarias y viales; Seguros Aconcagua; Seguros La Agrícola; Medicus Medicina Privada; Sociedad Argentina Constructora y las editoriales Emecé y Santillana. ${ }^{32}$

\section{CAMBIOS ESTRATÉGICOS EN LA CONDUCCIÓN EMPRESARIAL}

Desde su constitución en 1908 hasta el año 1978, el control del paquete accionario de LA estuvo en manos de las familias Braun y Menéndez, pasando de un alto grado de concentración a una mayor dispersión entre diversos miembros de ambas familias, hecho que se agudizó con la apertura

30 En un ranking elaborado para las 20 mayores empresas y grupos familiares de Argentina entre los años 1923 y 1954, la Sociedad Importadora y Exportadora de la Patagonia figuró en $8^{\circ}$ lugar en 1923 y en el $20^{\circ}$ en 1937, en tanto que la S. A. Menéndez Behety Ganadera Argentina ocupó el $11^{\circ}$ en 1923, el 14 en 1927 y el $6^{\circ}$ lugar en 1944/45 (Barbero \& Lluch, 2015).

31 En esos años, uno de los socios de la empresa era William Reynal, primo de Alejandro Reynal, integrante del equipo económico del ministro Martínez de Hoz, quien por entonces se desempeñaba como vicepresidente del Banco Central y fue el que gestionó la venta al Estado en un momento en que Austral estaba prácticamente en situación de quiebra.

32 Biblioteca MECON, Comisión Nacional de Valores, Sociedades Anónimas (https://www.argentina. gob.ar/cnv/empresas). 
del capital social a la oferta pública en 1942. A mediados de la década de 1960, en medio de una difícil situación económica y financiera, la sociedad tomó una serie de medidas tales como la liquidación de la flota naviera, la venta de campos e inmuebles y la transformación de los almacenes de ramos generales en supermercados. En 1979 se logró revertir la situación y el paquete accionario se concentró en la familia Braun, que asumió la conducción de la sociedad hasta la actualidad. El actual presidente y director delegado de LA, Federico Braun, hijo de Oscar y nieto de Mauricio, está vinculado a la empresa desde $1978 .^{33}$

El estatuto social prevé que el directorio esté compuesto por el número de miembros que fije la asamblea ordinaria entre un mínimo de cinco y un máximo de nueve, con una duración de sus respectivos mandatos de un año, previéndose la posibilidad de reelección indefinida. El grupo familiar Braun se asegura el control del $77 \%$ del capital social en circulación y el $79 \%$ del derecho a voto, con una clara estrategia orientada a obtener el liderazgo supermercadista en la región patagónica y su extensión a otras localidades del interior nacional, mediante una política de crecimiento, renovación tecnológica e informática y la instauración de una nueva estrategia corporativa con especial atención a la logística. ${ }^{34}$ Este último sector es responsable directo de las funciones de abastecimiento y distribución a los puntos de venta, para lo cual cuenta con una importante red de centros regionales de distribución y centros de transferencia de carga, ubicados estratégicamente de acuerdo a la distribución geográfica de sus locales de venta y de los centros de producción y distribución de sus proveedores..$^{35}$ En palabras de su propio presidente, fueron los primeros en lanzar una marca propia (Best) a partir de la producción de pequeñas y medianas empresas, así como en armar una logística de distribución eficiente contratando a

33 Su vicepresidente es Santiago Braun y sus directores titulares Juan José Badano, Pablo Dusserre, Pablo Braun, Nicolás Perkins y Roberto Gitard. La excelente posición de la empresa en los últimos años pueden verse en detalle en el Informe trimestral abril 2019. https://www.evaluadora.com/ar/ usr/archivos/1684_Imp\%20y\%20Exp\%20Patagonia.pdf

34 Los frigoríficos de la empresa estás ubicados en la ciudad de Salto, Provincia de Buenos Aires, con una antigüedad de doce años; y, desde finales del 2014, se cuenta con otros bajo la razón social Pampa Natural S. A., en la localidad de Speluzzi, en La Pampa, que abastecen al mercado interno y exportan a Alemania, Inglaterra, Italia, Bélgica, Portugal, Francia, Holanda y Suiza, entre otros. Ver: Estados Contables Anuales y Trimestrales; Comisión Nacional de Valores (www.cnv.gob.ar); Bolsa de Comercio de Buenos Aires (www.bolsar.com); Instituto Nacional de Estadísticas y Censos (www. indec.gov.ar).

35 Según información oficial de la empresa, LA cuenta actualmente 10 centros de distribución regionales, que abastecen diariamente a más de 130 puntos de venta propios y de terceros repartidos en la zona sur y centro del interior del país, y dos bases de transferencia de carga ubicadas en Buenos Aires (carga general) y Mendoza (frutas y verduras), que vinculan a los proveedores con la red de distribución (https://www.laanonima.com.ar/; consultado el 30/3/2021). 
diversas empresas de transporte, algunas muy pequeñas, a las que suelen brindarles apoyo crediticio para incrementar su inversión, a lo cual agregaron su propia tarjeta de compras y crédito. En resumen, una estrategia que no necesariamente se apoya en los niveles de la macroeconomía, sino que entiende que su negocio puede funcionar exitosamente a partir del consumo, aun cuando el producto bruto interno disminuya (entrevista a Federico Braun, en Urrutia \& Mottura, 2014).

Si ya en 1978 contaba con 11 sucursales, el año 1997 marca un momento importante de expansión de la empresa, al alcanzar las 57 sucursales. Pese a las declaraciones de su presidente sobre los efectos negativos de la crisis internacional de 2002, la SAlyEP muestra nuevamente una rápida recuperación. Con financiamiento nacional a través de los Créditos del Bicentenario, ${ }^{36}$ instaurados en 2010 por el gobierno de Cristina Fernández de Kirchner, incorporó 10 sucursales más en el año 2013 y ha seguido creciendo de forma acentuada en los últimos años. Cabe sumar a ello el posicionamiento político de dos familiares directos de Federico Braun, Miguel Braun y Marcos Peña Braun, quienes ejercieron como secretario de Comercio Interior y jefe de gabinete, respectivamente, del gobierno del expresidente Macri entre los años 2015 y 2019. ${ }^{37}$ Evidentemente, los cambios políticos en el país no parecen haber afectado el desenvolvimiento de la empresa.

Años antes, en 2010, la empresa vendió la cadena de minimercados Best, de la ciudad de Buenos Aires, a la empresa internacional Carrefour —aunque conserva, según vimos, el nombre como marca propia-, en una medida que se ajusta a su manifiesta política empresarial de focalizar la actividad comercial solo en pequeñas y medianas localidades. ${ }^{38}$ En 2014 contaba con 158 sucursales en 79 localidades del interior del país, ${ }^{39}$ sumando a ello los 10 centros

36 El objetivo del Programa del Bicentenario fue ofrecer fondos a largo plazo para mejorar la oferta de créditos a la inversión productiva, con un costo financiero fijo en pesos moneda nacional $(9,9$ $\%$ nominal anual). La mayor parte de estos créditos fueron otorgados por el Banco de la Nación Argentina. El acceso de la firma a los mismos fue mencionada en declaraciones de Federico Braun en una entrevista personal (Urrutia \& Mottura, 2014).

37 Federico Braun ha expresado a la prensa en varias ocasiones que la empresa no obtuvo condiciones favorables en este periodo, salvo en el rubro exportador. Justamente en ese rubro, diversas fuentes indican que fue favorecida por el Gobierno con una mayor participación en el cupo de exportación de carne vacuna premium a la Unión Europea, conocida como Cuota Hilton, lo cual le permitió aventajar al resto de sus competidores (Resolución 271-E/17 del Ministerio de Agroindustria que oficializó la distribución de un total de 25.444 toneladas de carne vacuna para ser exportadas en el marco de la Cuota Hilton 2017/18). El frigorífico de LA fue, al igual que en el periodo anterior, el principal ganador del cupo de exportación de cortes cárnicos de alto valor, obteniendo 113 toneladas más que en el ciclo 2016/17 (https://www.lapoliticaonline.com/ nota/108583/; https://archivo.valorsoja.com/).

38 Según declaraciones de su presidente, Federico Braun, en Urrutia y Mottura (2014).

39 Comisión Nacional de Valores (www.cnv.gob.ar). 
de distribución y una base de transferencia, una planta panificadora y otra fileteadora de fiambres, además de los dos frigoríficos de exportación, lo cual ya le había permitido posicionarse entonces como la cuarta empresa del rubro en el ámbito nacional y la segunda de bandera argentina.

En febrero de 2015, LA adquirió el fondo de comercio de la firma neuquina Centro Distribuidor del Comahue S. A. (Cedicom), obteniendo el traspaso de 25 sucursales de los supermercados locales Topsy y Bomba. ${ }^{40}$ Así mismo, durante el ejercicio cerrado en junio de 2015 se inauguraron nuevas sucursales, se remodelaron otras, y continuaron las inversiones en logística.

Además de presidir la SAlyEP, Federico Braun es actualmente presidente de Patagonia Logística S. A., Campos de la Patagonia S. A., Estancia Anita S. A., Club de Polo Los Pingüinos S. A.; vicepresidente del Club de Campo Los Pingüinos S. A., Pampa Natural S. A. y de la Asociación de Supermercados Unidos. Es asimismo director titular de Inmobiliaria y Financiera "La Josefina” S. A.; director suplente de Comercio Exterior, Importaciones y Exportaciones MARSEB SRL; vocal de la Asociación Empresaria Argentina y consejero vitalicio de la Fundación. Igualmente, es miembro del directorio de Grupo Galicia desde septiembre de 1999. ${ }^{41}$ Según información del año 2015, el grupo familiar conservaba un número importante de estancias en propiedad, como se detalla en el cuadro 3.

\footnotetext{
- Estancia Alta Vista (El Calafate, S. C.), 75.000 hectáreas (La Anónima S. A).

- Estancia Glencross (Río Penitentes, S. C.), 45.000 hectáreas (Menéndez).

- Estancia La Primavera (Río Turbio, S. C.), 20.000 hectáreas (Menéndez).

- Estancia Tapi-Aike (Río Turbio, S. C.), 60.000 hectáreas (Braun-Viel Temperley).

- Estancia Rospentek (Río Gallegos, S. C.), 90.000 hectáreas (Braun).

- Estancia Valle Huemules (Río Huemules, Cht.), 20.000 hectáreas (Behety-Milward).

- Estancia La Pepita, (Alto Río Senguerr, Cht.), 70.000 hectáreas (Menéndez-Braun).

- Estancia Quichaura (Tecka, Cht.), 117.000 hectáreas (Braun-Estrugamou).

- Estancias Laura y Laurita (Gobernador Costa, Cht.), 58.000 hectáreas (Braun-Lahusen).
}

Evidentemente, de lo que se deduce de estos registros, aunque la propiedad de estancias en manos de miembros de la familia ha disminuido con respecto a las inversiones iniciales, la posesión de más de 500.000 hectáreas

40 Evaluadora Latinoamericana, Agente de Calificación de Riesgos, SAlyEP, Informe trimestral abril 2019 (https://www.evaluadora.com/ar/usr/archivos/1684_Imp\%20y\%20Exp\%20Patagonia.pdf).

41 Toda la información antes referida se obtuvo del Grupo Financiero Galicia S. A. (http://www.gfgsa. com/es/Static/ManagementProfile?name=Federico\%20Braun; consultado el 14/1/2021)
Cuadro 3. Propiedades de los Braun-Menéndez

Fuente: tomado de http://www. polosproductivosreg.com. ar/2020/02/28/listado-de-losterratenientes-de-la-patagoniaargentina/ 
en las provincias patagónicas de Chubut y Santa Cruz, 75.000 de ellas en propiedad directa de LA, no es un dato menor. Ello garantiza a la empresa la producción cárnica en zonas libres de aftosa, no solo para abastecer a sus sucursales sino también para mantener las altas cuotas de exportación de cortes premium, de las cuales es beneficiaria.

\section{A MODO DE SÍNTESIS}

Sin duda, la obtención de tierras en condiciones muy ventajosas, cuando no gratuitas, sumada a la capitalización creciente a través de inversiones diversificadas, fueron las estrategias más importantes utilizadas por estos grupos familiares para afrontar su proceso de acumulación originaria y los distintos ciclos posteriores de la economía nacional e internacional. A ello, obviamente, se sumaron sus vínculos políticos, sociales y económicos con otros sectores regionales y con los poderes públicos de Chile y de Argentina, así como su capacidad para aprovechar la provisión de créditos y otros recursos financieros, muchas veces en forma independiente del posicionamiento partidario de los gobiernos de turno.

Igualmente, queda claro el hábil manejo familiar de la empresa, con más de cien años de existencia, y su gran capacidad de adaptación para la reproducción del patrimonio a través de las distintas generaciones, mediante una importante articulación de redes parentales con grupos prominentes a nivel regional y nacional, así como para hacer frente a las crisis económicas externas e internas, estas últimas derivadas del propio manejo empresarial. Sin duda, el grupo familiar Braun-Menéndez Behety supo aprovechar muy exitosamente las oportunidades económicas que ofrecía la excelente ubicación de Punta Arenas para proyectar desde allí una muy importante diversificación de inversiones, primero en la zona más austral de la Patagonia argentina, sin duda un área marginal y periférica en el modelo agroexportador dominante en el país en las primeras décadas del siglo XX, con indiscutible centro en la Pampa húmeda, para proyectarse luego al conjunto nacional.

La apertura del canal de Panamá, la Primera Guerra Mundial, la pérdida circunstancial de mercados europeos privilegiados, como es el caso del alemán, y la instalación de medidas fronterizas arancelarias por parte del Gobierno radical, motivaron un primer cambio de estrategia que derivó en el traslado de su sede central de Punta Arenas a la ciudad de Buenos 
Aires y su trasformación en empresa argentina en 1918, a lo cual se sumaron una serie de inversiones familiares diversificadas (primeros frigoríficos en la Patagonia austral, líneas navieras, comunicaciones, servicios, bancos), que permitieron a estos grupos no solo consolidar la presencia de la SAlyEP a nivel nacional, sino también conservar y acrecentar su patrimonio, superando rápidamente situaciones de crisis.

Efectivamente, a lo largo de las décadas de 1920 y 1930 la empresa mostró signos de una rápida recuperación de las crisis provocadas por la primera posguerra y por el derrumbe internacional de 1929-30, respectivamente. Pero en 1942, debido a una apertura del capital social a la oferta pública, que produjo incluso una mayor dispersión accionaria entre miembros de la propia familia, sufrió una importante crisis interna. No obstante, sobre fines de la década siguiente diversificó aún más sus inversiones (construcciones navales, ferroviarias y viales, línea aérea, seguros, medicina privada, editoriales), lo cual le permitió ocupar, según vimos, un lugar muy significativo en el ranking de las veinte empresas familiares más importantes del país hasta el año 1954. A comienzos de la década de 1960, la crisis se profundizó y la SAlyEP decidió vender parte de sus activos (liquidación de la flota naviera, venta de campos e inmuebles y la transformación de los almacenes de ramos generales en supermercados), lo que derivó en un nuevo cambio de estrategia en la conducción de la empresa concretado en 1979, con el objeto de lograr la concentración del patrimonio y de las acciones empresariales en manos de la familia Braun y de sus allegados más directos, quienes poseen en la actualidad la mayor parte del capital accionario y controlan la capacidad de decisión empresarial. Esto habría derivado, en las últimas décadas, en una centralización más significativa de sus inversiones en el sector comercial y en su logística específica, apuntando a satisfacer la demanda del mercado interno y a acrecentar su patrimonio financiero, a la vez que a incrementar su capacidad de exportación de cortes cárnicos de alta calidad.

La Anónima concentra hoy todos sus activos en Argentina, con más de 200 sucursales en puntos estratégicos del conjunto nacional. A ello suma la propiedad de estancias en zonas libres de aftosa y de empresas frigoríficas para la conservación, consumo y exportación de cárnicos, así como centros de distribución y transferencia de cargas, su propia tarjeta de crédito y el sostenimiento de una marca propia de bienes diversos de consumo masivo, producidos por pequeñas y medianas empresas asociadas. 
Aunque su presidente, Federico Braun, tiene, según vimos, actividades dirigenciales y acciones en distintas empresas, incluido el Banco Galicia, la SAlyEP concentra sus inversiones en el espacio comercial, lo cual le ha permitido convertirse en una de las empresas líderes del sector supermercadista nacional, compitiendo exitosamente con las más grandes cadenas internacionales bajo una lógica empresarial que apunta a ser eficiente en pequeñas y medianas localidades, y destinando sus mayores esfuerzos a la satisfacción de la demanda del consumo interno y a la exportación de carne, con lo cual le es posible sostener una capacidad financiera asegurada. Una de sus características específicas, que la distingue de otras empresas familiares que optaron por la internacionalización a fines de la década de 1970, es el haber apostado justamente a esa estrategia, que mantiene hasta la actualidad, logrando sostener y aumentar una posición privilegiada en el sector supermercadista nacional.

\section{REFERENCIAS}

Almaraz, A., \& Ramírez, L. (coords.) (2018). Familias empresariales en México. Sucesión generacional y continuidad en el siglo XX. Colegio de la Frontera Norte.

Bandieri, S. (comp.) (2005). Cruzando la cordillera... la frontera argentino chilena como espacio social. EDUCO, Editorial Universitaria UNCo.

Bandieri, S. (2005a). Del discurso poblador a la praxis latifundista: La distribución de la tierra pública en la Patagonia. Mundo Agrario, 6(11), 1-19.

Bandieri, S. (2015). Inversión multiimplantada: tierras, comercio y finanzas en la Patagonia austral. Revista Estudios del ISHIR, 5(13), 20-40. http:// revista.ishir-conicet.gov.ar/ojs/index.php/revistalSHIR/article/ view/574

Bandieri, S. (2018). Políticas de distribución de la tierra pública en la Patagonia. Leyes y prácticas (1876-1930). En G. Blanco (ed.), La tierra pública en la Patagonia. Normas, usos, actores sociales y tramas relacionales (pp. 27-60). Prohistoria.

Bandieri. S., \& Almaraz, A. (2020). Business families in southern Patagonia: from the end of the 19th Century to the first decades of 20th century. Journal of Evolutionary Studies in Business, 5(2), 33-79. 
Barbería, E. (1992). Chile y Argentina. Una región autárquica en el sur, 18801920. Waxen, 6, 1-43.

Barbería, E. (1996). Los dueños de la tierra en la Patagonia Austral, 1880-1920. Universidad Federal de la Patagonia Austral.

Barbero, M. I., \& Lluch, A. (2015). El capitalismo familiar en Argentina: modelos y dinámicas en el largo plazo. En P. Fernández-Pérez \& A. Lluch (eds.), Familias empresarias y grandes empresas familiares en América Latina y España. Una visión de largo plazo (pp. 219-258). Fundación BBVA.

Bascopé, J. (2008). Pasajeros del poder propietario. La Sociedad Explotadora de Tierra del Fuego y la biopolítica estanciera (1890-1920). Magallania, 36(2), 19-44. https://doi.org/10.4067/ S0718-22442008000200002

Bayer, O. (1972). Los vengadores de la Patagonia trágica (Tomos I, II y III). Galerna.

Blanco, G. (2007). La tierra pública y su ocupación en Neuquén: política distributiva, formas de tenencia y uso del suelo (1880-1920). Mundo Agrario, 7(14), 1-29. http://www.mundoagrario.unlp.edu.ar/article/ view/v07n14a10/1115

Cerutti, M. (2015). Grandes empresas y familias empresariales en México. En P. Fernández-Pérez \& A. Lluch (eds.), Familias empresarias y grandes empresas familiares en América Latina y España. Una visión de largo plazo (pp. 153-187). Fundación BBVA.

Chapman, A. (1983). The Selk 'nam of Tierra del Fuego. Cambridge University Press.

Coronato, F. (2018). De empleados a patrones. Ganaderos malvinenses en la Patagonia. En G. Blanco (ed.), La tierra pública en la Patagonia. Normas, usos, actores sociales y tramas relacionales (pp. 137-156). Prohistoria.

Dávila, C. (2015). La historia empresarial en América Latina. En C. Erro (dir.), Historia empresarial: pasado, presente y retos de futuro (pp. 263-268). Ariel.

Fernández-Pérez, P., \& Lluch, A. (eds.) (2015). Familias empresarias y grandes empresas familiares en América Latina y España. Una visión de largo plazo. Fundación BBVA. 
Fernández-Pérez, P., \& Valls, J. (eds.) (2017). Special Issue: New Perspectives in Family Business Research. Journal of Evolutionary Studies in Business, 2(2). http://revistes.ub.edu/index.php/JESB/issue/ view/1635

Gilbert, J. (2003). Entre la expansión y la crisis de la economía argentina. Ernesto Tornquist y Cía. Ciclos, Especial (25-26), 65-92.

Gilbert, J. (2009). Redes sociales y vínculos familiares en los orígenes del grupo Tornquist. Anuario CEEED, 1(1), 45-73. http://bibliotecadigital. econ.uba.ar/download/aceeed/aceeed_v1_n1_02.pdf

Granovetter, M. (1998). Coase Revisited: Business Groups in the Modern Economy. En G. Dosi, D. Teece, \& J. Chytry (eds.), Technology, Organization, and Competitiveness (pp. 67-104). Oxford University Press. https://doi.org/10.1093/0198290969.003.0003

Harambour, A. (2017). Soberanía y corrupción. La construcción del estado y la propiedad en la Patagonia austral (Argentina y Chile, 1840-1920). Historia, 50(2), 555-596. https://doi.org/10.4067/ s0717-71942017000200555

Lafuente, H. (2015). Tres reyes y una dama. La historia de Braun, Menéndez y Nogueira. Literarte.

Lluch, A., Rinaldi, A., Salvaj, E., \& Vasta, M. (2017). Directors and syndics in corporate networks: Argentina and Italy compared (1913-1990). Business History, 61(3), 603-628. https://doi.org/10.1080/00076791.20 17.1382474

López-López, A. (2011). Las empresas transnacionales en Argentina: del modelo agroexportador a las reformas estructurales. En G. Jones \& A. Lluch (eds.), El impacto histórico de la globalización en Argentina y Chile: empresas y empresarios (pp. 101-131). Editorial Temas.

Martínez-Echezárraga, J. (2015). Grandes familias empresariales en Chile. Sus características y aportes al país (1830-2012). En P. FernándezPérez \& A. Lluch (eds.), Familias empresarias y grandes empresas familiares en América Latina y España. Una visión de largo plazo (pp. 409-436). Fundación BBVA.

Martinic, M. (1975). Las actividades iniciales de José Menéndez, 1875-1885. Instituto de la Patagonia. 
Martinic, M. (1976). La expansión económica de Punta Arenas sobre los territorios argentinos de la Patagonia y Tierra del Fuego, 1885-1925. Anales Instituto de la Patagonia, 7, 5-42.

Martinic, M. (2005). Patagonia Austral: 1885-1925. Un caso singular y temprano de integración regional autárquica. En S. Bandieri (comp.), Cruzando la cordillera... la frontera argentino chilena como espacio social (pp. 459-486). EDUCO, Editorial Universitaria UNCo.

Ministerio de Agricultura de Argentina (1901). Digesto de Leyes, Decretos y Resoluciones relativas a tierras públicas, colonización, inmigración, agricultura y comercio, 1810-1900. Compañía Sudamericana de Billetes de Banco.

Monsalve-Zanatti, M. (ed.) (2014). Grupos económicos y medianas empresas familiares en América Latina. Universidad del Pacífico.

Moyano, D. (2015). Desde la empresa. Firmas familiares y estructura empresarial en la industria azucarera tucumana, 1895-1930. Prometeo.

Rodríguez-Satizabal, B. (2014). Grupos económicos en Colombia (19741998): Entre pequeña empresa familiar y gran familia de empresas. En M. Monsalve-Zanatti (ed.), Grupos económicos y medianas empresas familiares en América Latina (pp. 41-86). Universidad del Pacífico.

Ruffini, M. (2017). La Patagonia mirada desde arriba. El grupo BraunMenéndez Behety y la Revista Argentina Austral (1929-1967). Prohistoria.

Salvaj, E., Lluch, A., \& Gómez, C. (2017). La red empresarial chilena en 1939: entre la crisis global y la adaptación a la etapa de la industrialización promovida por el Estado. En M. Llorca-Jaña \& D. Barría, Empresas y empresarios en la historia de Chile, 1930-2015 (pp. 47-89). Editorial Universitaria.

Schvarzer, J. (1989). Bunge \& Born. Crecimiento y diversificación de un grupo económico. CISEA.

Urrutia, F., \& Mottura, D. (2014). Entrevista al presidente de La Anónima, Federico Braun. Socios, Revista de Economía y Negocios de la Patagonia, 1(1), 30-34. 
Vdal-Olivares, J. (2015). El estado y el impacto de las políticas económicas en la evolución histórica de las empresas familiares en España y América Latina. En P. Fernández Pérez \& A. Lluch (eds.), Familias empresarias y grandes empresas familiares en América Latina y España. Una visión de largo plazo (pp. 409-436). Fundación BBVA. 